\title{
APACHE IV system helps to determine cholecystostomy role in elderly patients with acute cholecystitis
}

Hua Jiang ( $\sim$ jianghua@xwhosp.org)

Xuanwu Hospital https://orcid.org/0000-0002-8838-7793

Guo Guo

Xuanwu Hospital

Zhimin Yao

Xuanwu Hospital

Yuehua Wang

Xuanwu Hospital

Research article

Keywords: Acute cholecystitis, Acute Physiology and Chronic Health Evaluation, APACHE IV, Elderly patients, Cholecystostomy

Posted Date: May 18th, 2020

DOI: https://doi.org/10.21203/rs.3.rs-27767/v1

License: (9) This work is licensed under a Creative Commons Attribution 4.0 International License. Read Full License

Version of Record: A version of this preprint was published at Journal of International Medical Research on November 1st, 2021. See the published version at https://doi.org/10.1177/03000605211059288. 


\section{Abstract \\ Background}

Cholecystostomy offers an alternative method for patients unfit to undergo immediate cholecystectomy. Nevertheless, the role of cholecystostomy in the clinical management of high-risk surgical patients remains unclear. One of the main problems concerning the therapeutic effect in critically ill patients with acute cholecystitis is the lack of validated, well-established scoring systems to stratify the severity of patient disease states. APACHE IV scoring system was useful to estimate the hospital mortality for highrisk patients. We try to evaluate the performance of the APACHE IV scoring system in patients over 65 years of age with acute cholecystitis and the therapeutic effect of percutaneous cholecystostomy.

\section{Methods}

597 patients over 65 years of age with acute cholecystitis between January 2011 and December 2018 were retrospectively analyzed with the APACHE IV scores.

\section{Results}

Among the 597 patients, 52 successfully underwent cholecystectomy ( 2 died, 3.85\%), 65 underwent percutaneous cholecystostomy ( 1 died, $1.54 \%$ ), and 480 received conservative therapy (27 died, 5.63\%). The fitness of the APACHE IV score prediction is good with the area under the ROC curve of 0.894 . The APACHE IV models were well-calibrated (with the Hosmer-Lemeshow statistic). Using the method of binary regression analysis, for the patients whose estimated mortality rate was more than $10 \%$, cholecystostomy was an important factor for prognosis $(P=0.048)$. The estimated mortality of PC patients before and after operation was compared, which indicated that the estimated mortality after puncture was significantly decreased, either in the whole patient group $(P=0.004)$ or in the group with an estimated mortality greater than $10 \%(P=0.008)$.

\section{Conclusion}

The APACHE IV scoring system showed that cholecystostomy was a safe and effective treatment for elderly high-risk patients with acute cholecystitis.

\section{Background}

Acute cholecystitis (AC) is a very heterogeneous disease and its life-threatening potential is strongly determined by the general status of the patient. In the aging subpopulation with medical comorbidities, immediate definitive surgery may be hazardous. Percutaneous cholecystostomy (PC) offers an alternative method of management for patients unfit to undergo immediate cholecystectomy because of 
severe sepsis or other underlying comorbidity. ${ }^{[1]}$ Linet et al. ${ }^{[2]}$ reported that the rate of PC markedly increased from $0.5 \%$ in 2005 to $12.2 \%$ in 2015 and was more common among the elderly. Smith et al. ${ }^{[3]}$ also reported an increased use of PC in patients with AC over a 20-year period. Nevertheless, evidence for the role of gallbladder drainage as an effective alternative to early surgery remains poor, and there have been no randomized controlled trials on the issue ${ }^{[4]}$. Lu et al. ${ }^{[5]}$ reported that the mortality rates were far higher in patients undergoing PC than in patients undergoing cholecystectomy. PC appeared to be of little benefit and not as safe as the Tokyo guidelines have suggested. ${ }^{[6]}$ To date, it remains difficult to determine the role of PC in the clinical management of high-risk surgical patients with $A C$ based on the currently available evidence. At present, the World Society of Emergency Surgery does not recommend PC among routine protocols for treatment of acute cholecystitis until better evidence becomes available. ${ }^{[7]}$ Various definitions are used to identify "high-risk patients", and the result also makes it more difficult to investigate the role of PC.

Outcome prediction is useful for therapeutic decision-making in critically ill patients. APACHE IV, the latest version of the APACHE (Acute Physiology and Chronic Health Evaluation) scoring system published in 2006, was developed to estimate the hospital mortality for adult ICU admissions. The APACHE IV score consists of several parts, including diagnosis, chronic health status, age, vital signs and physiologic measures, including blood gas analysis, urine output, blood sugar, WBC count, bilirubin level, and others; these are all not only accurate and reproducible but are also related to the prognosis of patients with $A C^{[8]}$, especially elderly $A C$ patients. The aim of this study was to evaluate the performance of the APACHE IV scoring system in patients over 65 years of age with AC and the therapeutic effect of percutaneous cholecystostomy.

\section{Methods}

This study was approved by the ethics review board of the Xuanwu Hospital of Capital Medical University of China. All patients signed informed consent. Consecutive patients admitted to our hospital (a 1200-bed urban tertiary-care referral center with a 12-bed surgical ICU) for the treatment of acute cholecystitis diagnosed by Tokyo guidelines diagnostic criteria ${ }^{[9]}$ between January 2011 and December 2018 were retrospectively analyzed. The diagnosis of acute cholecystitis was based on clinical symptoms (right upper quadrant or epigastric pain or tenderness), leukocytosis or raised C-reactive protein (CRP) and at least one of the following sonographic findings: distended gallbladder, gallbladder wall thickening $>3 \mathrm{~mm}$ or debris in the gallbladder. ${ }^{[10]}$ Patients who were admitted with acute cholecystitis were identified by International Classification of Diseases (ICD)-9 diagnosis code. The exclusion criteria included (1) patients with acute pancreatitis or choledocholithiasis; (2) patients with malignancy of the bile duct, gallbladder, liver, or pancreas; (3) patients younger than 65 years old; (4) patients with missing values and the APACHE score could not be calculated. The data were collected from each patient on the day of admission to compute the APACHE IV scores, and the worst values for each parameter in the first 24-hour period were used. Hospital mortality was defined as the death of patients before discharge from the 
hospital. The decision to perform PC or cholecystectomy were made by the hepatobiliary surgeons based on their experience and the will for surgery on the part of the patients.

PC was performed by a hepatobiliary surgeon who used ultrasound guidance under local anesthesia. First, a Chiba needle was introduced transhepatically into the gallbladder; second, the guidewire was placed, and the track was sequential dilated; then, the 7-Fr pigtail catheter was positioned with its tip in the gallbladder. The PC catheter was left open, connected to a collection bag and drained by gravity. After 2 weeks, if the patient's symptoms were relieved, the PC tube would be clipped. After 2 months, the PC tube can be preserved in situ or removed during cholecystectomy. Conservative treatment mainly included antibiotic treatment, fasting and nutritional support. Cholecystectomy was carried out according to conventional methods, $94.3 \%$ of them were performed by laparoscopy, $5.7 \%$ by laparotomy, no patients underwent subtotal cholecystectomy.

\section{Statistical analysis}

Data were analyzed using SPSS 21 software. Continuous variables are expressed as the mean \pm standard deviation, and categorical variables are expressed as frequencies and percentages. The area under the ROC curve was used to compare the accuracy of the studied models. The t-test and Rank sum test were used for inter group comparisons, and $\mathrm{P}<0.05$ was considered statistically significant. We used the Hosmer-Lemeshow goodness-of-fit test to evaluate the calibration prediction fitness. Binary regression analysis was performed to identify predictors of mortality rate.

\section{Results}

A total of 862 consecutive patients with AC were enrolled in this study, of which 265 patients were excluded. Among the latter, 124 had choledocholithiasis, 108 had acute pancreatitis, 5 had cholangiocarcinoma, 3 had gallbladder cancer and 25 had incomplete APACHE IV data. The patients' origins before ICU admission were the emergency department $(521 / 597,87.30 \%)$ and the inpatient units (76/597, 12.70\%).

This study included 597 patients with a mean age of 75.88 years; 30 patients died during hospitalization, resulting in a mortality rate of $5.03 \%$. Because of China's national conditions, many patients choose conservative treatment instead of emergency cholecystectomy or cholecystostomy. Among the 597 patients, 52 successfully underwent cholecystectomy within 72 hours of the onset of disease ( 2 died, $3.85 \%), 65$ underwent percutaneous cholecystostomy guided by US within 7 days of the onset of disease ( 1 died, $1.54 \%$ ), and 480 received conservative therapy (27 died, 5.63\%). Dislodged drainage tubes were found in two patients in the PC group (3.08\%) without signs of bile leakage; two cases (3.08\%) of bleeding after PC were cured by conservative treatment; no other procedure-related complications were found in the other patients with PC or cholecystectomy. Fifty-four of the 64 survivors (84.38\%) in the PC group had cholecystectomy approximately 2 months after discharge from the hospital, while the other 7 survivors (10.94\%) only removed the drainage tube; the remaining 3 survivors (4.68\%) kept the drainage 
tube. There were no obvious complications in the 54 patients who underwent cholecystectomy post PC, none of the other 10 patients died of gallbladder-related diseases until now.

The characteristics of the patients, along with a comparison of the survivors and nonsurvivors, are described in Table 1. Many details about patients, including leukocyte, transaminase, bilirubin, blood gas analysis and so on have been included in Apache IV score, so we do not list them in detail. The survivors were younger and had lower APACHE IV scores and lower risks of death than did the nonsurvivors. The discrimination of the APACHE IV score prediction was good with an AUC of 0.894 ( $95 \% \mathrm{Cl}, 0.849-0.930$, Fig. 1). The Youden index was 0.62 , the sensitivity was $78.26 \%$, the specificity was $83.33 \%$. The APACHE IV models were well-calibrated (with the Hosmer-Lemeshow statistic, chi-squared $=8.179,8$ degrees of freedom, and $P=0.416)$; the data are shown in Fig. 2.

Table 1

Comparison of Survivors to Nonsurvivors with acute cholecystitis over 65 years

\begin{tabular}{|c|c|c|c|c|}
\hline & $\begin{array}{l}\text { Overall }(n= \\
597)\end{array}$ & $\begin{array}{l}\text { Survivors }(\mathrm{n}= \\
567)\end{array}$ & $\begin{array}{l}\text { Nonsurvivors }(n= \\
30)\end{array}$ & P value \\
\hline Mean( \pm SD) & $75.88( \pm 8.24)$ & $75.54( \pm 8.11)$ & $83.03( \pm 7.92)$ & 0.001 \\
\hline \multicolumn{5}{|l|}{ Age (y) } \\
\hline Mean APACHE $\triangle$ Score $( \pm$ SD) & $\begin{array}{l}39.19( \pm \\
14.17)\end{array}$ & $38.19( \pm 13.33)$ & $61.82( \pm 12.58)$ & 0.001 \\
\hline $\begin{array}{l}\text { Mean Estimated Mortality (\% } \\
\pm \text { ISD) }\end{array}$ & $8.21( \pm 7.66)$ & $7.47( \pm 6.78)$ & 23.92( \pm 11.24$)$ & 0.001 \\
\hline
\end{tabular}

Using the method of binary regression analysis for all patients, we found that the two surgical treatments (cholecystectomy $[P=0.173]$ and $P C[P=0.684]$ ) had no significant effects on mortality. Because death is a serious event, we chose various levels of estimated mortality to further examine our data; the details are shown in Table 2. When the estimated mortality rate was more than $10 \%$ or $12.5 \%, \mathrm{PC}$ was an important factor in prognosis for patients with relatively severe illness $(P=0.048$ and $P=0.049)$; however, cholecystectomy did not show relation with reduced mortality in the same population $(P=0.479$ and $P=$ 0.277). The estimated mortality of PC patients before and after operation was compared, which indicated that the estimated mortality after puncture was significantly decreased, either in the whole patient group $(P=0.004)$ or in the group with an estimated mortality greater than $10 \%(P=0.008)$. The details are shown in Table 3. 
Table 2

The affection of cholecystectomy and cholecystostomy on different Estimated mortality groups

\begin{tabular}{|c|c|c|c|c|}
\hline & \multicolumn{3}{|c|}{ Overall Patients $(n=597)$ AUC $₫ 0.894$} & \multirow{2}{*}{$\begin{array}{l}\mathrm{P} \\
\text { value }\end{array}$} \\
\hline & $\begin{array}{l}\text { Survivors } \\
(n=567)\end{array}$ & $\begin{array}{l}\text { Nonsurvivors } \\
(n=30)\end{array}$ & $\begin{array}{l}\text { Mean Estimated } \\
\text { Mortality(\%) }\end{array}$ & \\
\hline cholecystectomy & $50(96.15 \%)$ & $2(3.85 \%)$ & 4.1 & 0.173 \\
\hline cholecystostomy & $64(98.46 \%)$ & $1(1.54 \%)$ & 12.43 & 0.684 \\
\hline \multirow[t]{3}{*}{ conservation } & $453(94.38 \%)$ & $27(5.62 \%)$ & 8.87 & 0.174 \\
\hline & \multicolumn{3}{|c|}{ Patients with estimated mortality $>5.0 \%(n=298)$} & \multirow{2}{*}{$\begin{array}{l}\mathrm{P} \\
\text { value }\end{array}$} \\
\hline & $\begin{array}{l}\text { Survivors } \\
(\mathrm{n}=269)\end{array}$ & $\begin{array}{l}\text { Nonsurvivors } \\
(\mathrm{n}=29)\end{array}$ & $\begin{array}{l}\text { Mean Estimated } \\
\text { Mortality }(\%)\end{array}$ & \\
\hline cholecystectomy & $9(90 \%)$ & $1(10 \%)$ & 10.04 & 0.977 \\
\hline cholecystostomy & $29(96.67 \%)$ & $1(3.33 \%)$ & 10.91 & 0.212 \\
\hline \multirow[t]{3}{*}{ conservation } & $231(89.53 \%)$ & $27(10.47 \%)$ & 13.79 & 0.278 \\
\hline & \multicolumn{3}{|c|}{ Patients with estimated mortality $>7.5 \%(n=176)$} & \multirow{2}{*}{$\begin{array}{l}\mathrm{P} \\
\text { value }\end{array}$} \\
\hline & $\begin{array}{l}\text { Survivors } \\
(n=149)\end{array}$ & $\begin{array}{l}\text { Nonsurvivors } \\
(\mathrm{n}=27)\end{array}$ & $\begin{array}{l}\text { Mean Estimated } \\
\text { Mortality }(\%)\end{array}$ & \\
\hline cholecystectomy & $3(75 \%)$ & $1(25 \%)$ & 15.13 & 0.588 \\
\hline cholecystostomy & $17(100 \%)$ & $0(0 \%)$ & 14.37 & 0.065 \\
\hline conservation & $129(83.23 \%)$ & $26(16.77 \%)$ & 18.83 & 0.152 \\
\hline \multicolumn{4}{|c|}{ Patients with estimated mortality $>10 \%(n=140)$} & \multirow{2}{*}{$\begin{array}{l}P \\
\text { value }\end{array}$} \\
\hline & $\begin{array}{l}\text { Survivors } \\
(n=115)\end{array}$ & $\begin{array}{l}\text { Nonsurvivors } \\
(n=25)\end{array}$ & $\begin{array}{l}\text { Mean Estimated } \\
\text { Mortality }(\%)\end{array}$ & \\
\hline cholecystectomy & $2(66.67 \%)$ & $1(33.33 \%)$ & 17.58 & 0.479 \\
\hline cholecystostomy & $16(100 \%)$ & $0(0 \%)$ & 14.72 & 0.048 \\
\hline conservation & $97(80.16 \%)$ & $24(19.83 \%)$ & 21.64 & 0.123 \\
\hline \multicolumn{4}{|c|}{ Patients with estimated mortality $>12.5 \%(n=122)$} & \multirow{2}{*}{$\begin{array}{l}\mathrm{P} \\
\text { value }\end{array}$} \\
\hline & Survivors $(n=98)$ & $\begin{array}{l}\text { Nonsurvivors } \\
(n=24)\end{array}$ & $\begin{array}{l}\text { Mean Estimated } \\
\text { Mortality }(\%)\end{array}$ & \\
\hline cholecystectomy & $1(50.00 \%)$ & $1(50.00 \%)$ & 20.42 & 0.277 \\
\hline cholecystostomy & $15(100 \%)$ & $0(0 \%)$ & 15.21 & 0.049 \\
\hline conservation & $83(78.30 \%)$ & $23(21.70 \%)$ & 23.09 & 0.147 \\
\hline
\end{tabular}


Table 3

Comparison of Estimated Mortality of patients before and after cholecystostomy

All cholecystostomy patients $(n=65)$

$\mathbf{P}$

value

before surgery

$12.43( \pm 3.92)$

Mean Estimated Mortality(\%)

$( \pm \mathrm{SD})$

Cholecystostomy patients with Estimated Mortality $>10 \%$

$(n=16)$

before surgery

$14.72( \pm 2.72)$

$( \pm$ SD)
$4.8( \pm 2.20)$

0.004

\section{after surgery}

after surgery

$4.46( \pm 1.89)$

0.008

\section{Discussion}

As the prevalence of acute cholecystitis increases with the increasing elderly population, we pay more attention both to the old patients with AC. One of the main problems concerning the role of PC is the lack of validated, well-established scoring systems to stratify the severity of patient disease states and different definitions are used to identify "high-risk patients". The authors of the Tokyo guidelines suggested a staging system using mild, moderate and severe, depending upon the degree of local inflammation and the patients' conditions ${ }^{[11-13]}$. However, a retrospective series failed to find any significant benefit from the application of the Tokyo guidelines ${ }^{[14]}$. Amirthalingam et al. concluded that the Tokyo guidelines 2013 may be too restrictive for patients with moderate and severe acute cholecystitis, and more attention should be paid to patient comorbidities during clinical decision-

making ${ }^{[15]}$. Yacoub et al. tried to develop a score to stratify patients with gangrenous cholecystitis but did not pay much attention to the comorbidities of the patients; their score cannot be applied to patients who do not desire surgery ${ }^{[16]}$. We propose the APACHE IV score as a good tool to stratify and compare elderly patients with AC in clinical trials, and our study results indicate that this is possible ${ }^{[8]}$. For most hospitals, there are no conditions or data to establish their own evaluation criteria, therefore it is convenient and accurate to apply APACHE IV scoring in their clinical wards.

Although laparoscopic cholecystectomy is considered the gold standard treatment for patients with AC, it remains difficult to make definitive recommendations regarding treatment by PC or cholecystectomy in elderly or critically ill patients. A recent review reported a particularly detailed examination of 53 papers regarding cholecystostomy as an option in acute cholecystitis, and suggested that PC was beneficial in high-risk patient groups, predominantly as a bridging therapy, allowing safer elective cholecystectomy once the patient has recovered from the acute illness ${ }^{[17]}$. Our data agree with this suggestion, as the 
procedure can stabilize the patient so that appropriate therapeutic planning can be achieved. There are reports that, in patients with acute cholecystitis who presented to the hospital $\geq 72$ hours after symptom onset and did not respond to nonoperative treatment for 48 hours, PC with delayed laparoscopic cholecystectomy produced better outcomes and fewer complications than did emergency laparoscopic cholecystectomy. ${ }^{[18]}$ Our experience partly confirmed this argument. In this group of data, the number of patients with predicting high mortality in both the PC group and the cholecystectomy group is too small, and the comparison between the two surgical methods is not statistically accurate, so we did not make this comparison. More data are wanted to clarity this question.

In a randomized controlled trial by Hatzidakis, ${ }^{[19]}$ the efficacy of PC was compared with that of conservative management; the authors suggested that PC should not be performed as the first choice in patients with acute cholecystitis, since it did not produce lower mortality rates than did conservative treatment. They also suggested that PC should be appealing to patients not showing clinical improvement following 3 days of conservative treatment, as well as to critically ill intensive care unit patients ${ }^{[19]}$. Their results were in harmony with ours. For patients in mild or moderate condition, we did not find PC superior to conservative treatment. One reason for the indistinguishability is that the death rates were very low; on the other hand, conservative treatment did have a good effect. We suggest more precise indications for PC with the estimated mortality rate more than $10 \%$. Of these eligible patients, PC was associated with reduced mortality. Early recognition and intervention are required in these patients, because of the rapid progression of acute cholecystitis to gangrene and perforation. We believe our indications are more concise and suitable for clinical work.

In previous studies of the safety of PC, procedure-related complications were only about $6.25 \%$, relatively low considering candidates are usually high-risk patients. In our study, we found procedure-related complications in elderly patients with AC were only $7.16 \%$, comparable to those of previous reports. ${ }^{[20]}$ Although urgent cholecystectomy (within 72 hours from symptom onset) has been proposed as a definitive treatment for symptomatic gallbladder disease, ${ }^{[21]}$ routine cholecystectomy in an emergency setting can be challenging. Rather, gallbladder puncture is a better choice for surgeons with less experience. PC is a comparatively safe and effective procedure for the treatment of not only elderly highrisk patients with serious comorbidities but also for patients with contraindications for the general anesthesia required for cholecystectomy. ${ }^{[22]}$

Our study has two major limitations. First, although this is the first external validation of the APACHE IV admission prognostic model in elderly patients with AC, it is a nonrandomized and retrospective study. Second, this research was done in China. Among the 597 patients, $480(80.40 \%)$ received conservative managements rather that the surgical management that they should have had according to the international guidelines. This was mainly due to patients' unwillingness to operate and lack of experienced surgeons and this may have impacted on the patient prognosis. The study in itself has limitation in the external validity and its purpose is to compare PC to conservative treatment, excluding the patients who underwent cholecystectomy. Further studies will be required to elucidate this point. 


\section{Conclusion}

The APACHE IV scoring system showed that PC puncture was a safe and effective treatment for high-risk elderly patients with acute cholecystitis. The conservative treatment was acceptable for the milder forms of the disease, but the most severe forms need a more aggressive treatment. More precise systems to predict mortality in AC patients are welcome as they can help therapeutic decision-making and enrollment of patients in clinical trials.

\section{Abbreviations}

AC

Acute cholecystitis; Acute Physiology and Chronic Health Evaluation;

APACHE

Acute Physiology and Chronic Health Evaluation

PC

Percutaneous cholecystostomy

\section{Declarations}

\section{Availability of data and materials}

The datasets used and/or analyzed during the current study are available from the corresponding author on reasonable request.

\section{Ethics approval and consent to participate}

All patients gave written informed consent according to the 1975 declaration of Helsinki. The study was approved by the ethics review board of the Xuanwu Hospital of Capital Medical University of China. (2006-2017).

\section{Consent for publication}

The authors all approved the manuscript for publication.

\section{Competing interests}

The authors declare that they have no competing interest.

\section{Funding}


The authors disclosed receipt of no financial support for the research.

\section{Contributions}

Hua Jiang: Study design, analysis and interpretation of data, manuscript preparation. Guo Guo, Zhimin Yao and Yuehua Wang: Clinical examinations and data acquisition, revision of the manuscript. All authors provided critical revision of the manuscript for important intellectual content and read and approved the final manuscript.

\section{Acknowledgements}

Not applicable.

\section{Financial disclosures:}

Drs. Hua Jiang, Guo Guo, Zhimin Yao and Yuehua Wang stated that they do not have any conflicts of interest or financial ties to disclose.

\section{References}

1. Chung YH, Choi ER, Kim KM, et al. Can percutaneous cholecystostomy be a definitive management for acute acalculous cholecystitis. J Clin Gastroenterol. 2012;46(3):216-9.

2. Lin WC, Chang $\mathrm{CW}, \mathrm{Chu} \mathrm{CH}$. Percutaneous cholecystostomy for acute cholecystitis in high-risk elderly patients. Kaohsiung J Med Sci. 2016;32(10):518-25.

3. Smith TJ, Manske JG, Mathiason MA, Kallies KJ, Kothari SN. Changing trends and outcomes in the use of percutaneous cholecystostomy tubes for acute cholecystitis. Ann Surg. 257(6). United States,2013. 1112-5.

4. Campanile FC, Catena F, Coccolini F, et al. The need for new "patient-related" guidelines for the treatment of acute cholecystitis. World J Emerg Surg. 2011;6(1):44.

5. Lu P, Chan CL, Yang NP, Chang NT, Lin KB, Lai KR. Outcome comparison between percutaneous cholecystostomy and cholecystectomy: a 10-year population-based analysis. BMC Surg. 2017;17(1):130.

6. Rodríguez-Sanjuán JC, Arruabarrena A, Sánchez-Moreno L, González-Sánchez F, Herrera LA, GómezFleitas M. Acute cholecystitis in high surgical risk patients: percutaneous cholecystostomy or emergency cholecystectomy. Am J Surg. 2012;204(1):54-9.

7. Ansaloni L, Pisano M, Coccolini F, et al. 2016 WSES guidelines on acute calculous cholecystitis. World J Emerg Surg. 2016;11:25. 
8. Jiang H, Yao Z, Guo G, Wang Y, Li F. APACHE IV Score is Useful For Assessment and Stratification of Elderly Patients Over 65 Years With Acute Cholecystitis. Surg Laparosc Endosc Percutan Tech. 2019;29(6):524-8.

9. Miura F, Takada T, Strasberg SM, et al. TG13 flowchart for the management of acute cholangitis and cholecystitis. J Hepatobiliary Pancreat Sci. 2013;20(1):47-54.

10. Al-Jundi W, Cannon T, Antakia R, et al. Percutaneous cholecystostomy as an alternative to cholecystectomy in high risk patients with biliary sepsis: a district general hospital experience. Ann $\mathrm{R}$ Coll Surg Engl. 2012;94(2):99-101.

11. Yokoe M, Takada T, Strasberg SM, et al. New diagnostic criteria and severity assessment of acute cholecystitis in revised Tokyo Guidelines. J Hepatobiliary Pancreat Sci. 2012;19(5):578-85.

12. Hirota $M$, Takada $T$, Kawarada $Y$, et al. Diagnostic criteria and severity assessment of acute cholecystitis: Tokyo Guidelines. J Hepatobiliary Pancreat Surg. 2007;14(1):78-82.

13. Mayumi T, Takada T, Kawarada Y, et al. Results of the Tokyo Consensus Meeting Tokyo Guidelines. J Hepatobiliary Pancreat Surg. 2007;14(1):114-21.

14. Lee SW, Yang SS, Chang CS, Yeh HJ. Impact of the Tokyo guidelines on the management of patients with acute calculous cholecystitis. J Gastroenterol Hepatol. 2009;24(12):1857-61.

15. Amirthalingam V, Low JK, Woon W, Shelat V. Tokyo Guidelines 2013 may be too restrictive and patients with moderate and severe acute cholecystitis can be managed by early cholecystectomy too. Surg Endosc. 2017;31(7):2892-900.

16. Yacoub WN, Petrosyan M, Sehgal I, Ma Y, Chandrasoma P, Mason RJ. Prediction of patients with acute cholecystitis requiring emergent cholecystectomy: a simple score. Gastroenterol Res Pract. 2010. 2010: 901739.

17. Winbladh A, Gullstrand P, Svanvik J, Sandström P. Systematic review of cholecystostomy as a treatment option in acute cholecystitis. HPB (Oxford). 2009. 11(3): 183-93.

18. Karakayali FY, Akdur A, Kirnap M, Harman A, Ekici Y, Moray G. Emergency cholecystectomy vs percutaneous cholecystostomy plus delayed cholecystectomy for patients with acute cholecystitis. Hepatobiliary Pancreat Dis Int. 2014;13(3):316-22.

19. Hatzidakis AA, Prassopoulos P, Petinarakis I, et al. Acute cholecystitis in high-risk patients: percutaneous cholecystostomy vs conservative treatment. Eur Radiol. 2002;12(7):1778-84.

20. Jang WS, Lim JU, Joo KR, Cha JM, Shin HP, Joo SH. Outcome of conservative percutaneous cholecystostomy in high-risk patients with acute cholecystitis and risk factors leading to surgery. Surg Endosc. 2015;29(8):2359-64.

21. Komatsu S, Tsuchida S, Tsukamoto T, et al. Current role of percutaneous transhepatic gallbladder aspiration: from palliative to curative management for acute cholecystitis. J Hepatobiliary Pancreat Sci. 2016;23(11):708-14.

22. Leveau P, Andersson E, Carlgren I, Willner J, Andersson R. Percutaneous cholecystostomy: a bridge to surgery or definite management of acute cholecystitis in high-risk patients. Scand J Gastroenterol. 2008;43(5):593-6. 
Figures

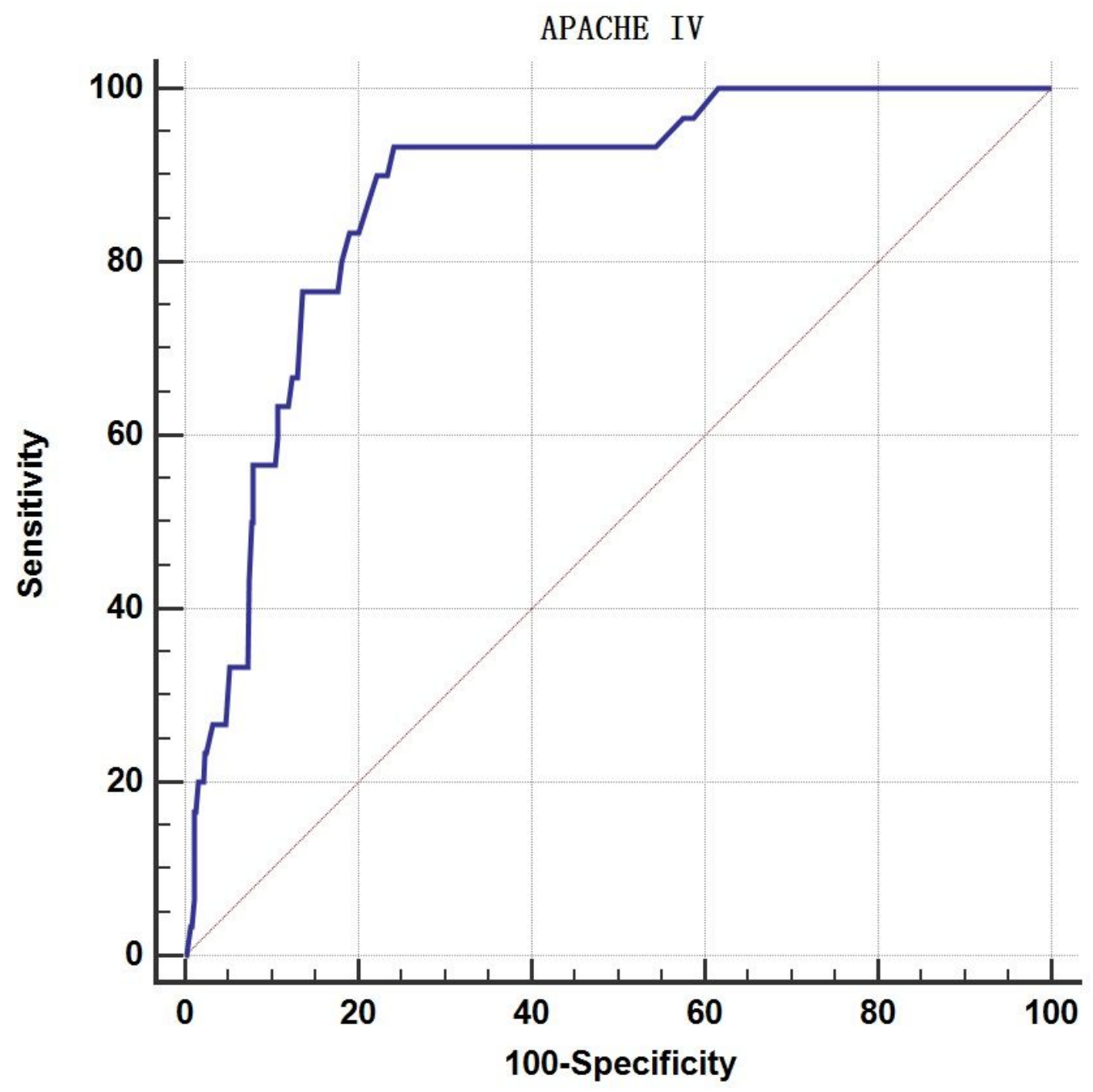

Figure 1

Receiver operating characteristic curve for the APACHE IV score of the overall patients. The AUC was $0.878(95 \% \mathrm{Cl}, 0.780$ - 0.932). 


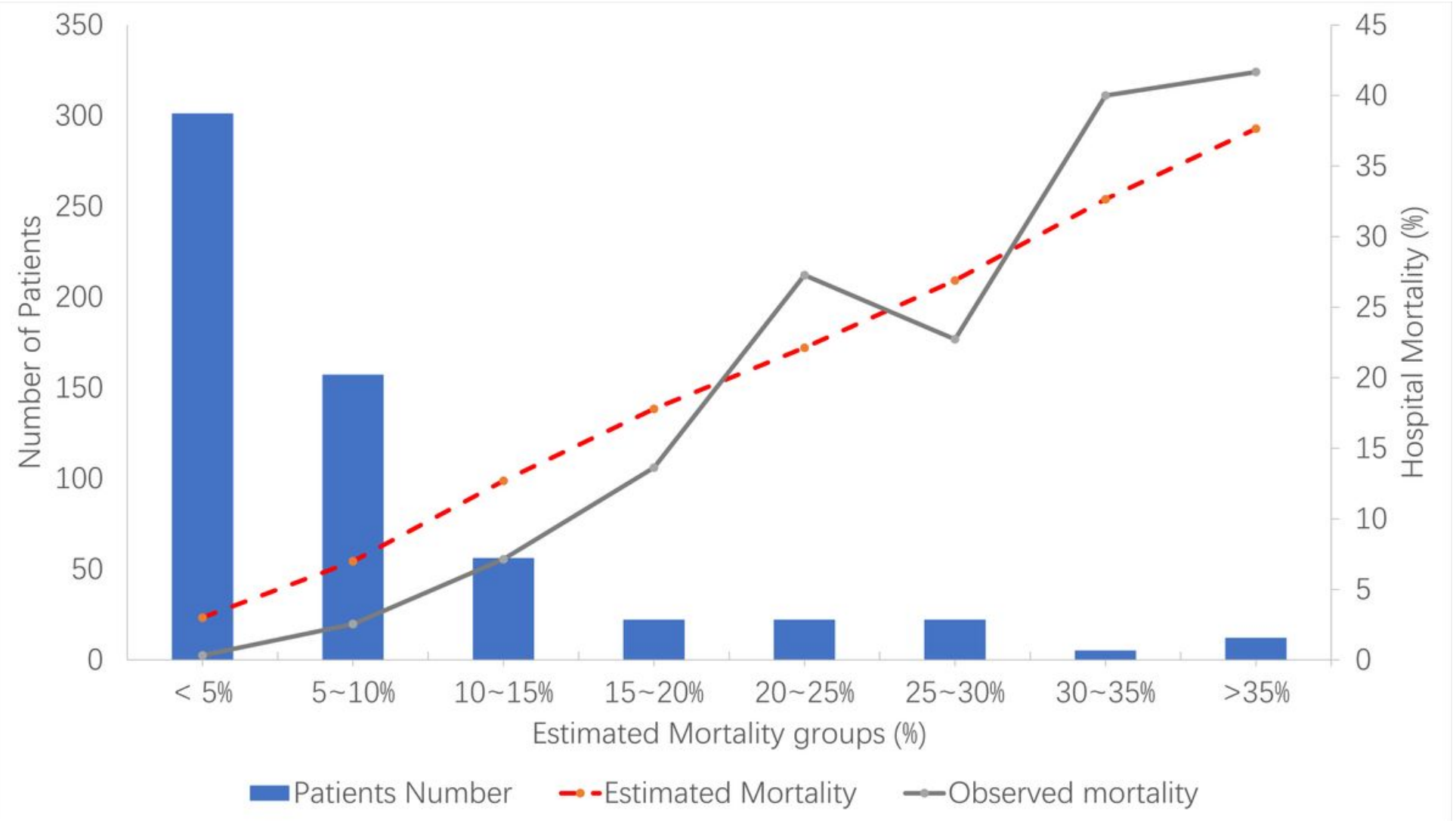

\section{Figure 2}

Calibration curve of APACHE IV models for all 597 patients. The numbers of patients in each group are shown in the columns, and the actual mortality rate and estimated mortality rate of each group are shown as real and imaginary broken lines respectively. The fitting degree is good (with the HosmerLemeshow statistic, $P=0.416)$. 